\title{
Rezim Kerjasama Sosek Malindo Kaltim-Sabah: Mengukur Derajat Compliance Partisipan Perjanjian
}

\section{Sonny Sudiar}

Program Studi Hubungan Internasional, Fakultas IImu Sosial dan IImu Politik Universitas Mulawarman, Samarinda, 75119

Email: bandarost@gmail.com

\begin{abstract}
Sosek Malindo cooperation is mutual agreement between Indonesia and Malaysia that concentrated in the field of socio-economic development in border areas. The main objective of Sosek Malindo cooperation is to improve the welfare of the people who live in border areas of each country. Sosek Malindo Cooperation produce some agreements, but not all of them can be implemented, because of compliance problems. The failure was caused by several factors, among others: the limited authority of the actor, the factor of interest, in managing the agreement Sosek Malindo regime does not use persuasive methods. Moreover it has serious implications to the implementation of agreement and actor behavior. Keywords: Compliance, Regime, Sosek Malindo
\end{abstract}

\section{Abstrak}

Kerjasama Sosek Malindo adalah kesepakatan antara Indonesia dan Malaysia yang memfokuskan pada pengembangan bidang sosial-ekonomi di area perbatasan. Tujuan utama dari kerjasama ini adalah untuk meningkatkan kesejahteraan rakyat yang tinggal di area perbatasan di masing-masing negara. Kerjasama ini menghasilkan beberapa kesepakatan, namun tidak semuanya bisa dilaksanakan karena masalah penyesuaian. Kegagalan itu disebabkan oleh beberapa faktor, antara lain kewenangan terbatas aktor, faktor kepentingan dalam mengatur kerjasama dan tidak menggunakan metode persuasif. Terlebih lagi terdapat dampak serius terhadap pelaksanaan perjanjian dan prilaku aktor.

Kata kunci: penyesuaian, rezim, Sosek Malindo

\section{PENDAHULUAN}

Kerjasama internasional merupakan salah satu elemen yang sangat penting dalam pelaksanaan kebijakan dan politik luar negeri Republik Indonesia. Melalui kerjasama-kerjasama internasional baik secara bilateral maupun multilateral, Indonesia diharapkan dapat memanfaatkan peluang-peluang untuk menunjang dan melaksanakan pembangunan nasionalnya (Direktorat Jenderal Kerjasama Asean. 2007: i).

Pembangunan memang sebuah keniscayaan yang harus dilakukan untuk alasan kemajuan dan perubahan untuk menjadi lebih baik. Dengan demikian pembangunan menjadi sebuah proses yang senantiasa harus dilakukan oleh setiap pemerintahan sebuah negara untuk memperbaiki dan meningkatkan kualitas hidup masyarakatnya. Gagasan pembangunan pada hakikatnya adalah gagasan mengenai peningkatan taraf hidup manusia ke tingkat yang lebih baik, lebih sejahtera, lebih nyaman dan lebih tentram, serta lebih menjamin kelangsungan hidup masyarakat di hari depan (Husein, 1986: 1).

Begitu pun adanya dengan Indonesia, pembangunan mutlak harus terus digalakkan agar negeri ini dapat terbebas dari masalah ketertinggalan yang terus menghantuinya. Adapun agenda 
pembangunan yang paling mendesak adalah pembangunan di wilayah perbatasan Indonesia.

Kawasan perbatasan negara adalah wilayah kabupaten/kota yang secara geografis dan demografis berbatasan langsung dengan negara tetangga dan/atau laut lepas. Kawasan perbatasan terdiri dari kawasan perbatasan darat dan laut, yang tesebar secara luas dengan tipologi yang sangat beragam (Kementerian Perencanaan Pembangunan Nasional/BAPPENAS. 2010: 63).

Secara geografis, Indonesia memiliki beberapa wilayah perbatasan dengan negara-negara tetangga, baik berupa daratan maupun lautan (pulau-pulau terluar). Indonesia berbatasan dengan 10 (sepuluh) negara tetangga, yaitu: India, Malaysia, Singapura, Thailand, Vietnam, Filipina, Australia, Timor Leste, Palau, dan Papua Nugini. Secara keseluruhan kawasan perbatasan dengan negara tetangga tersebar di 12 (dua belas) provinsi (Kementerian Perencanaan Pembangunan Nasional/BAPPENAS. 2010: 63). Namun hanya ada 4 (empat) daerah yang memiliki perbatasan darat dengan negara-negara lain, yakni: Provinsi Kalimantan Barat, Provinsi Kalimantan Timur, Provinsi Nusa Tenggara Timur, dan Provinsi Papua (Koespramoedyo dkk, 2003: 1).

Wilayah-wilayah tersebut pada hakekatnya memiliki arti yang sangat vital dan strategis, baik dalam sudut pandang pertahanan-keamanan, maupun dalam sudut pandang ekonomi, sosial, dan budaya. Masing-masing wilayah perbatasan tersebut memiliki karakter sosial budaya dan ekonomi yang relatif berbeda antara satu dengan yang lainnya. Namun secara keseluruhan memperlihatkan adanya fenomena yang hampir sama, yakni adanya interaksi langsung dan intensif antara warga negara Indonesia dengan warga negara tetangga, berupa hubungan-hubungan sosial kultural secara tradisional maupun dalam bentuk kegiatan-kegiatan ekonomi modern (Koespramoedyo dkk, 2003: 1).

Salah satu wilayah perbatasan Indonesia yang mempunyai tingkat aktivitas dan interaksi perdagangan-ekonomi cukup tinggi adalah perbatasan antara Provinsi Kalimantan Timur dengan Negeri Sabah. Hal tersebut dapat dilihat dari perdagangan tradisional yang sudah lama terjadi antar masyarakat di perbatasan Indonesia dan Malaysia.

Hubungan kerjasama bilateral dengan Malaysia ini merupakan salah satu kerjasama internasional yang perlu dimaksimalkan oleh Indonesia sebagai upaya untuk meng-catch up peluang-peluang yang dihasilkan dari proses kerjasama tersebut. Salah satu kerjasama bilateral yang terjalin antara Indonesia-Malaysia adalah forum kerjasama Sosial Ekonomi Malaysia-Indonesia (Sosek Malindo). Kerjasama ini berkonsentrasi pada bidang pembangunan sosial-ekonomi di daerah perbatasan. Tujuan utama dari perjanjian kerjasama Sosek Malindo adalah untuk memperbaiki tingkat kesejahteraan masyarakat yang hidup di daerah perbatasan masing-masing negara.

Kerjasama Sosek Malindo pertama kali dimulai pada tahun 1985 di perbatasan Kalbar-Serawak. Kemudian tahun 1995 di perbatasan Kaltim-Sabah. Setelah memasuki tahun yang ke-15 jalinan kerjasama Sosek Malindo tingkat daerah Kaltim-Sabah telah mengalami proses hubungan kerjasama yang sangat dinamis. Banyak program kerjasama yang telah disepakati oleh kedua pihak dalam perjanjian kerjasama Sosek Malindo ini.

Dalam dinamika perkembangannya, hingga saat ini terdapat 7 kertas kerja yang telah disepakati antara Pemprov Kaltim dengan Pemerintah Negeri Sabah, yang meliputi beberapa bidang kerjasama, yaitu: bidang pembangunan PLBL, pembangunan PLBD, pencegahan dan penanggulangan kegiatan penyelundupan, hubungan sosial-budaya, bidang pendidikan, bidang kesehatan, dan bidang ekonomi-perdagangan.

Kesepakatan-kesepakatan yang sudah diambil dalam kerjasama tersebut ada yang sudah dapat dilaksanakan, namun ada pula yang masih belum/tidak dapat dilaksanakan, diantaranya adalah kesepakatan pembangunan Pos Lintas Batas Laut di Sungai Imam Pasir Putih, Tawau, Malaysia dan pembangunan Pos Lintas Batas Darat di Serudong, Malaysia. ${ }^{1}$

Fakta empirik tersebut tentu saja dapat berpengaruh pada kondisi dan perkembangan kehidupan sosialmasyarakat di daerah perbatasan kedua negara. Terdapatnya kesepakatan yang tidak dilaksanakan oleh 
pihak yang bekerjasama ini menunjukkan adanya perilaku yang tidak patuh (compliance problem). Situasi seperti apa yang sesungguhnya melatarbelakangi terjadinya tindakan non-compliance tersebut.

Gambaran ini mengindikasikan bahwa rezim Sosek Malindo Kaltim-Sabah tidak memiliki instrumen yang mempunyai kapabilitas untuk mengkondisikan agar setiap partisipan perjanjian internasional mempunyai tanggung jawab dan kewajiban mau untuk melaksanakan semua kesepakatan yang telah dibuat. Oleh karena itu, problem kepatuhan (compliance problem) dari masing-masing pihak dalam melaksanakan semua hasil kesepakatan menjadi concern utama yang ingin dikaji lebih dalam penelitian ini.

\section{REZIM INTERNASIONAL}

Rezim internasional merupakan sebuah konsekuensi logis dari kerjasama internasional. Rezim biasanya dibuat untuk mengatur kerjasama agar menjadi lebih efektif mengingat tingkat interdependensi antar aktor yang sangat rumit dan komplek. Oleh karena itu, dibentuknya rezim internasional merupakan sebuah upaya untuk menciptakan kerangka kerjasama internasional dan untuk memfasilitasi proses pembuatan kebijakan yang dapat dilakukan bersama.

Menurut Stephen Krasner rezim internasional adalah suatu tatanan yang berisi kumpulan prinsip, norma, aturan, dan prosedur pembuatan kebijakan baik yang berupa eksplisit maupun implisit, yang berkaitan dengan ekspektasi dan kepentingan aktor dalam hubungan internasional. Seperti yang dinyatakan dalam tulisannya:

International regimes are defined as a set of implicit or explicit principles, norms, rules, and decision making procedures around which actors' expectations converge in a given area of international relations. Principles are beliefs of fact, causation, and rectitude. Norms are standards of behavior defined in terms of rights and obligations. Rules are specific prescriptions or proscriptions for action.

Decision-making procedures are prevailing practices for making and implementing collective choice (Olson $\mathbb{E}$ Groom, 1991: 198).
Dalam formula lain Donald J. Puchala dan Raymond F. Hopkins (1982) menyatakan bahwa rezim internasional mempunyai 5 ciri utama, yaitu: Pertama, rezim mempunyai kemampuan untuk membentuk perilaku kepatuhan terhadap prinsip-prinsip, norma dan aturan. Rezim bersifat subjektif, dia hanya bisa eksis berdasarkan pemahaman, ekspektasi dan keyakinan para partisipannya mengenai legitimasi, kelayakan atau perilaku yang bermoral; Kedua, rezim internasional dapat menciptakan mekanisme/prosedur bagi pembuatan kebijakan. Karakteristik ini menunjukkan bahwa rezim internasional bukan hanya sekedar berisikan norma substantif. Tapi lebih dari itu, rezim internasional adalah tentang bagaimana prinsipprinsip tersebut dibuat yang melibatkan unsur-unsur seperti siapa partisipannya, kepentingan apa yang mendominasi atau yang menjadi prioritas, dan aturan apa yang dapat melindungi dari dominasi dalam proses pembuatan kebijakan; Ketiga, sebuah rezim selalu mempunyai prinsip-prinsip yang dapat menguatkannya, sebagaimana halnya sebuah norma dapat menetapkan kebenaran dan melarang perilaku yang menyimpang; Keempat, dalam setiap rezim selalu terdapat aktor yang berperan di dalamnya. Partisipan (aktor utama) dalam kebanyakan rezim internasional adalah pemerintahan negara-bangsa, akan tetapi tidak menutup kemungkinan juga ada dari aktor-aktor nonnegara. Peran mereka sebagai partisipan sangat krusial, yakni menciptakan, menjalankan, dan mematuhi aturan yang telah dibuat; Kelima, eksistensi rezim internasional adalah untuk mencocok nilai-nilai, tujuan-tujuan, dan prosedur pembuatan kebijakan yang dapat mengakomodir kepentingan dan kebutuhan semua partisipan (Puchala \& Hopkins, 1992: 62-63).

Konsep rezim internasional dalam penelitian ini dimaksudkan untuk menjelaskan dan mengukur keberadaan dinamika perjanjian kerjasama Sosek Malindo tingkat daerah Kaltim-Sabah sebagai rezim internasional yang telah disepakati oleh kedua anggotanya. 


\section{TEORI COMPLIANCE}

Konseksuensi yang muncul dari dibuatnya sebuah perjanjian internasional adalah tentang perilaku para partisipan yang menyepakatinya untuk konsisten dalam memenuhi semua kesepakatan yang dibuat dalam perjanjian internasional tersebut. Dalam situasi seperti ini, tentunya dibutuhkan upaya-upaya kooperatif dari masing-masing negara anggota yang membuat perjanjian internasional. Bentuk dari upaya kooperatif yang dimaksud adalah kepatuhan (compliance) terhadap kesepakatan.

Abram Chayes dan Antonia Handler Chayes telah menegaskan ada 3 (tiga) alasan utama yang mendorong sebuah negara mengambil tindakan untuk mematuhi perjanjian internasional, yaitu: efisiensi, kepentingan dan norma (Chayes, \& Chayes, 1995: 4). Sementara situasi yang memicu untuk tidak mematuhi kesepakatan, antara lain: pertama, ambiguitas dan tidak tepatnya bahasa yang digunakan dalam perjanjian; kedua, keterbatasan kapasitas partisipan tentu saja sangat berpengaruh pada tingkat kepatuhan terhadap perjanjian; ketiga, perjanjian internasional biasanya bersifat temporal dikarenakan perubahan signifikan yang terjadi dalam struktur sosial, sistem ekonomi dan kondisi politik.

Dalam studi tentang compliance terdapat dua aliran yang saling bertetangan satu sama lain, yaitu: enforcement school dan management school. Menurut aliran enforcement bahwa tindakan non-compliance terhadap perjanjian internasional dapat terjadi dalam berbagai motif. Compliance baru bisa terjadi jika aturan ditegakkan dan disertai dengan adanya sanksi (punishment). Strategi ini cukup efektif agar perjanjian dapat terlaksana, karena setiap pihak mengetahui jika melanggar atau tidak mematuhi perjanjian maka dia akan mendapatkan sanksi. Berbeda dengan aliran enforcement, aliran management justru menegaskan bahwa kepatuhan (compliance) dapat terjadi tanpa harus menyertakan strategi sanksi (punishment) dalam formulasi perjanjian, karena dianggap tidak efektif (Jonsson E Tallberg, 1998: 374).

Permasalahan compliance sebenarnya memang lebih tepat dianggap sebagai permasalahan pengelolaan (management) daripada permasalahan pelaksanaan (enforcement). Munculnya tindakan non-compliance terhadap rezim bukan tidak sengaja, akan tetapi lebih disebabkan oleh kurangnya kapabilitas, kejelasan dan prioritas kesepakatan dalam perjanjian. Untuk itu dibutuhkan strategi pengelolaan yang sophisticated contohnya dengan menggunakan metode persuasi. Adapun elemen yang dibutuhkan dalam metode ini antara lain: transparency, dispute settlement, capacity building. Keberadaan tiga elemen ini dalam sebuah perjanjian internasional diyakini bisa menstimulan munculnya perilaku compliance (Chayes, $\mathcal{F}$ Chayes, 1995: 22-25).

Teori compliance dalam penelitian ini digunakan untuk mengukur derajat kepatuhan dari masing-masing pihak yang membuat kesepakatan. Lebih lanjut teori ini berupaya untuk menjelaskan dinamika implementasi rezim kerjasama Sosek Malindo, serta difungsikan untuk menganalisis prosedur/mekanisme dan strategi pengelolaan kesepakatan.

\section{PEMBAHASAN}

Kondisi Umum di Wilayah Perbatasan Kaltim

Perbatasan Kalimantan merupakan perbatasan yang saat ini lebih banyak permasalahannya jika dibandingkan dengan wilayah perbatasan Indonesia lainnya. Secara keseluruhan panjang wilayah Kalimantan yang berbatasan langsung dengan Negara Bagian Serawak dan Sabah (Malaysia) lebih kurang $1.200 \mathrm{~km}$. Dari panjang garis perbatasan tersebut 70,58 persen berada di wilayah Provinsi Kalimantan Barat atau sepanjang lebih kurang 847,3 km dan melintasi 5 (lima) daerah Kabupaten, yaitu: Sambas, Bengkayang, Sanggau, Sintang dan Kapuas Hulu, yang meliputi 14 daerah kecamatan. Sedangkan perbatasan Provinsi Kalimantan Timur dengan Negara Bagian Sabah dan Negara Bagian Serawak sepanjang lebih kurang sekitar $850 \mathrm{~km}$ yang meliputi 3 (tiga) daerah Kabupaten yaitu: Kutai Barat, Malinau dan Nunukan yang meliputi 9 kecamatan (Koespramoedyo dkk, 2003: 4).

Kawasan perbatasan Kalimantan Timur meliputi kawasan pantai dan laut dan daratan yang terdiri dari 
Tabel 1

Dinamika Kerjasama Sosek Malindo

\begin{tabular}{ll}
\hline PERIODE & PERKEMBANGAN KERJASAMA \\
\hline 1967 & Awal kerjasama perbatasan di bidang keamanan \\
1972 & Revisi pertama perjanjian kerjasama kemananan perbatasan \\
1984 & Revisi kedua: Perluasan kerjasama perbatasan di bidang: \\
& sosial, politik, budaya, ekonomi \\
1985 & Terbentuknya Forum Kerjasama Sosek Malindo. Ditandai \\
1995 & dengan dimulainya Sosek Malindo Kalbar-Serawak \\
\hline
\end{tabular}

Sumber: diolah dari berbagai data sekunder

pegunungan. Dengan wilayah Negara Bagian Serawak terdapat pegunungan Iban membujur dari utara ke selatan dan membelok ke barat, di pegunungan Kapuas Hulu. Ada pula pegunungan Batu Ayu, membujur dari timur ke barat. Pada bagian utara di Kecamatan Pulau Sebatik berbatasan dengan Malaysia Timur, sedangkan Kabupaten Nunukan berbatasan laut dengan Kota Tawau. Jarak antara pelabuhan Nunukan dan Pelabuhan Tawau, Negara Bagian Sabah sekitar 30 kilometer. Pembangunan ekonomi di kawasan ini belum optimal, aktivitasnya kebanyakan masih bersifat lokal dan tradisional, dan belum berorientasi eksport. Hal ini disebabkan adanya kendala infrastruktur, kelembagaan, terbatasnya permodalan dan teknologi yang dimiliki, serta masih rendahnya kualitas dan kuantitas SDM setempat (Ishak. 2003: 15).

\section{DINAMIKA DAN STRUKTUR KERJASAMA SOSEK MALINDO KALTIM-SABAH}

Perdagangan lintas batas yang terjadi di perbatasan Kaltim-Sabah memiliki frekuensi yang cukup tinggi. Oleh karena itu, untuk mengatur lalu-lintas barang (perdagangan tradisional) antar masyarakat perbatasan, maka kedua pemerintahan baik Republik Indonesia dan Kerajaan Malaysia pun membuat sebuah kesepakatan berupa Border Trade Agreement (BTA) atau "Perjanjian Tentang Perdagangan Lintas Batas antara Pemerintah Republik Indonesia dengan Kerajaan
Malaysia.” Perjanjian tersebut ditandatangani pada tanggal 24 Agustus 1970 di Jakarta. Salah satu isi kesepakatannya berupa kerjasama Sosial Ekonomi Malaysia Indonesia atau disingkat menjadi Sosek Malindo.

Adapun visi dari kerjasama Sosek Malindo ini adalah: "Meningkatkan kesejahteraan masyarakat kedua daerah melalui kerjasama Sosek Malindo menuju 2020.” Agar visi kerjasama ini dapat direalisasikan, maka misi yang dilaksanakan adalah: pertama, menciptakan kondisi sosial ekonomi dan budaya yang kondusif bagi kesejahteraan masyarakat masing-masing daerah; kedua, meningkatkan kerjasama ekonomi yang berkeadilan dan saling menguntungkan serta berorientasi kelestarian lingkungan; ketiga, meningkatkan kerjasama sosial budaya lewat peningkatan kualitas dan pemberdayaan SDM di kedua daerah perbatasan (Irewati, 2005: 87-88).

Lebih lanjut data yang menunjukkan tentang kerjasama perbatasan antara Indonesia dengan Malaysia dapat dilihat pada tabel 1:

Tabel di atas menunjukkan bahwa kerjasama perbatasan antara dua negara Republik IndonesiaMalaysia pada awalnya dimulai dengan bidang keamanan pada tahun 1967, perjanjian ini kemudian direvisi untuk pertama kali pada tahun 1972, dan direvisi kembali pada tahun 1984. Revisi kedua kerjasama perbatasan antara Republik IndonesiaMalaysia mengalami perluasan area cakupan kerjasama 


\section{Gambar 1}

\section{Struktur Organisasi Sosek Malindo}

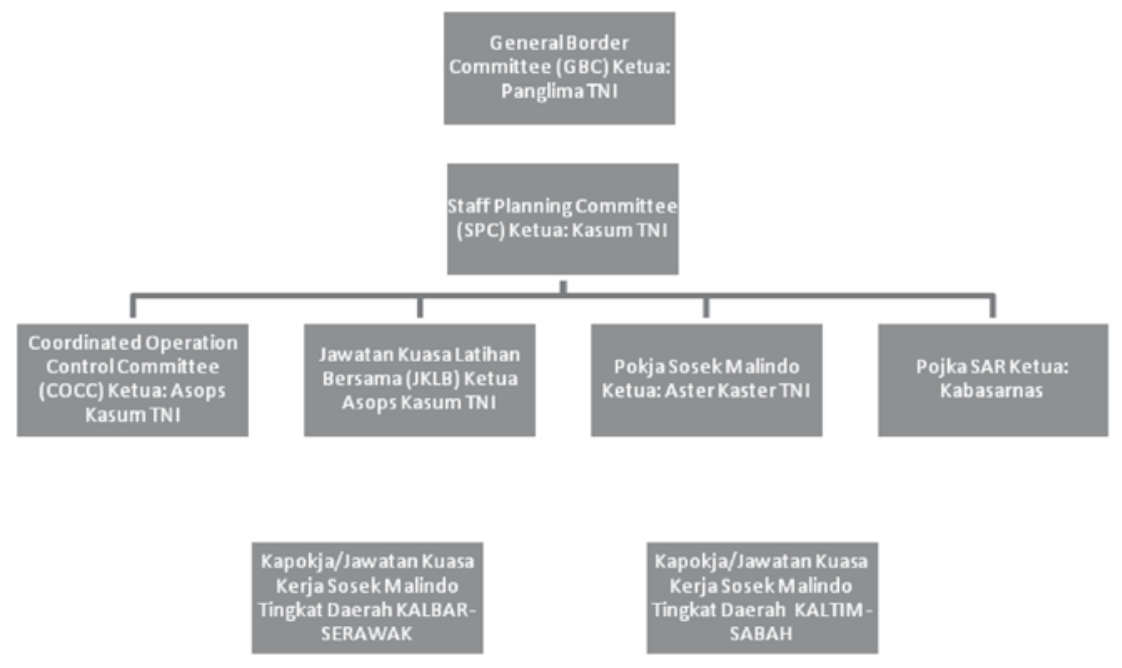

hingga mencakup berbagai bidang yaitu ideologi, politik, sosial, budaya, ekonomi.

Menindaklanjuti kesepakatan tersebut, maka tahun 1985 dibentuk forum kerjasama sosial ekonomi daerah (Sosekda) Provinsi Kalimantan Barat-Negeri Serawak, dan Sosekda Provinsi Kalimantan TimurNegeri Sabah dimulai sejak tahun 1995 (Asaddin, http:www. tastawima.com). Hubungan kerjasama Sosek Malindo tingkat daerah Kaltim-Sabah yang dimulai sejak tahun 1995 sampai sekarang masih terus berlangsung. Memasuki tahun ke-15 hubungan kerjasama ini mengalami dinamika yang sangat berwarna, dan tentunya banyak sudah programprogram kerja yang telah disepakati dalam upaya meningkatkan kesejahteraan masyarakat di masingmasing perbatasan di kedua negara.

Forum kerjasama Sosek Malindo ini mengadakan program pertemuan setahun sekali dengan tempat saling bergantian antara Indonesia dan Malaysia. Dalam strukturnya, Sosek Malindo diketuai oleh General Border Committee (GBC) di masing-masing negara dan untuk Indonesia Ketua GBC dipimpin oleh Panglima TNI. Di bawah struktur GBC tersebut telah dibentuk pula sebuah kelompok kerja (KK) Sosek Malindo di tingkat daerah provinsi/peringkat negeri ${ }^{2}$ yang dimaksudkan untuk: menentukan proyek-

proyek pembangunan sosial ekonomi yang digunakan bersama, merumuskan hal-hal yang berhubungan dengan pelaksanaan pembangunan sosial ekonomi di wilayah perbatasan, melaksanakan pertukaran informasi mengenai proyek-proyek pembangunan sosial ekonomi di wilayah perbatasan bersama, meyampaikan laporan kepada KK Sosek Malindo tingkat pusat mengenai pelaksanaan kerjasama pembangunan sosial ekonomi di wilayah perbatasan (Koespramoedyo dkk, 2003: 27).

Selain dikoordinasikan oleh Panglima TNI selaku ketua GBC Indonesia, KK Sosek Malindo juga melibakan Menteri Luar Negeri masing-masing negara selaku ketua Joint Committee Meeting (JCM) dan Menteri Dalam Negeri Republik Indonesia untuk membicarakan kerjasama bilateral dan pengembangan wilayah perbatasan Kalimantan antara pemerintah Malaysia dan pemerintah RI. Struktur organisasi Sosek Malindo dapat dilihat pada gambar 1:

\section{TUJUH KERTAS KERJA SOSEK MALINDO KALTIM-SABAH \\ Sampai dengan persidangan terakhir KK/JKK Sosek Malindo tingkat daerah Pemerintah Provinsi Kalimantan Timur dan peringkat Negeri Bagian Sabah telah bersepakat untuk melaksanakan beberapa pro- gram kerja yang bertujuan untuk meningkatkan}


Tabel 2

Derajat Compliance Dalam Kesepakatan Sosek Malindo Kaltim-Sabah

\begin{tabular}{|c|c|c|c|}
\hline \multirow{2}{*}{$\begin{array}{l}\text { IMPELENTASI } \\
\text { KESEPAKATAN }\end{array}$} & \multicolumn{2}{|c|}{ DERAIAT COMPLIANCE } & \multirow{2}{*}{ KETERANGAN } \\
\hline & INDONESIA & MALAYSIA & \\
\hline KK 1: Pembangunan PLBL & Patuh & tidak patuh & $\begin{array}{l}\text { Malaysia tidak melanjutkan } \\
\text { pembangunan PLBL di lokasi yang } \\
\text { telah ditentukan }\end{array}$ \\
\hline KK 2: Pembangunan PLBD & Patuh & tidak patuh & $\begin{array}{l}\text { Malaysia tidak melanjutkan } \\
\text { pembangunan PLBD di lokasi yang } \\
\text { telah ditentukan }\end{array}$ \\
\hline $\begin{array}{l}\text { KK 3: Pencegahan } \\
\text { Penyelundupan }\end{array}$ & Patuh & Patuh & $\begin{array}{l}\text { Kedua pihak melaksanakan butir } \\
\text { kesepakatan }\end{array}$ \\
\hline KK 4: Hubungan Sosial & Patuh & Patuh & $\begin{array}{l}\text { Kedua pihak melaksanakan butir } \\
\text { kesepakatan }\end{array}$ \\
\hline KK 5: Pendidikan & Patuh & Patuh & $\begin{array}{l}\text { Kedua pihak melaksanakan butir } \\
\text { kesepakatan }\end{array}$ \\
\hline KK 6: Kesehatan & Patuh & Patuh & $\begin{array}{l}\text { Kedua pihak melaksanakan butir } \\
\text { kesepakatan }\end{array}$ \\
\hline $\begin{array}{l}\text { KK 7: Ekonomi dan } \\
\text { Perdagangan }\end{array}$ & Patuh & Patuh & $\begin{array}{l}\text { Kedua pihak melaksanakan butir } \\
\text { kesepakatan }\end{array}$ \\
\hline
\end{tabular}

Sumber: diolah dari berbagai data sekunder

kesejahteraan masyarakat di daerah perbatasan masingmasing negara.

Adapun program kerja yang disepakati seperti yang tertuang dalam tujuh kertas kerja, yaitu; Kertas Kerja Pos Lintas Batas Laut (PLBL), Kertas Kerja Pos Lintas Batas Darat (PLBD), Kertas Kerja Pencegahan dan Penanggulangan Kegiatan Penyelundupan, Kertas Kerja Hubungan Sosial, Kertas Kerja Bidang Pendidikan, Kertas Kerja Bidang Kesehatan, Kertas Kerja Bidang Ekonomi dan Perdagangan (Asaddin. Sinergitas Pengembangan Potensi. http:www.tastawima.com).

Meskipun kedua belah pihak telah berhasil menyepakati tujuh kertas kerja dalam perjanjian kerjasama Sosek Malindo tingkat daerah Provinsi Kalimantan Timur-Negeri Sabah, namun masih ada hasil kesepakatan yang belum/tidak dapat dilaksanakan. Terhambatnya realisasi kesepakatan kerjasama tersebut lebih disebabkan oleh tiga kendala utama, yaitu; struktur kerjasama, mekanisme pengambilan keputusan kerjasama, fokus dan lingkup lokasi usulan kesepakatan.

\section{DERAJAT COMPLIANCE PARTISIPAN PERJANJIAN}

Hasil penelitian menunjukkan bahwa 7 (tujuh) kertas kerja yang telah disepakati dalam perjanjian kerjasama Sosek Malindo Kaltim-Sabah, setidaknya telah ditemukan ada 2 (dua) hasil kesepakatan yang tidak dapat terlaksana secara komprehensif, yaitu: kertas kerja 1: PLBL di Sungai Imam (Malaysia) dan Sungai Lamijung (Indonesia); dan kertas kerja 2: PLBD di Simanggaris (Indonesia) dan Serudong (Malaysia). Sebagaimana yang terlihat pada tabel 2:

Tidak terlaksananya 2 (dua) kesepakatan seperti yang tertulis pada tabel di atas lebih dikarenakan oleh perilaku pihak Malaysia yang tidak melakukan pembangunan di lokasi yang telah disepakati bersama. Kondisi tersebut tentu saja menunjukkan adanya perilaku non-compliance yang dilakukan pihak Malaysia terhadap hasil kesepakatan. Sementara di lain pihak, Indonesia telah berupaya maksimal untuk mematuhi hasil kesepakatan, dengan mewujudkan pembangunan Pos Lintas Batas Laut (PLBL) dan Pos Lintas Batas Darat (PLBD) di lokasi-lokasi yang telah ditentukan. Rampungnya pembangunan PLBL di Sungai Lamijung dan pembangunan infrastruktur pendukung seperti: jalan, drainase dan jembatan menuju PLBD di Simanggaris yang hingga saat ini masih terus dilakukan adalah bukti keseriusan pihak Indonesia dalam melaksanakan hasil kesepakatan.

Rendahnya derajat kepatuhan (compliance) Malaysia dalam merealisasi hasil kesepakatan bisa jadi karena proyek pembangunan infrastuktur perbatasan bukan 
dari bagian kepentingan prioritas mereka. Sehingga terkesan ada indikasi perilaku yang cenderung menyepelekan proyek-proyek rencana pembangunan infrastruktur tersebut. Argumentasi ini diperkuat oleh bukti-bukti empirik yang terjadi di lapangan, bahwa tidak terdapat kemajuan yang signifikan pada proyek pembangunan infrastruktur PLBL di Sungai Imam maupun PLBD di Serudong.

Lebih lanjut agar tidak muncul impresi negatif yang berkaitan dengan ketidakapatuhannya, pihak Malaysia kemudian berupaya untuk mengalihkan isu kesepakatan, dengan mencari alternatif solusi atas ditundanya/tidak jadinya pembangunan infrastruktur tersebut. Untuk permasalahan PLBL, pihak Malaysia membuat penawaran baru dengan membatalkan proyek pembangunan pelabuhan Sungai Imam, dan sebagai kompensasinya pihak Malaysia bersedia menaikkan nilai transaksi perdagangan di Pelabuhan Tawau. Motif yang melatarbelakangi perilaku ini tentunya adalah kepentingan ekonomi, karena dengan menaikkan nilai transaksi perdagangan merupakan peluang besar Malaysia untuk memasarkan produknya ke Indonesia. Khusus untuk kasus pembangunan fasilitas Pos Lintas Batas Darat (PLBD) di Serudong, setelah melakukan studi kelayakan pihak Malaysia menyimpulkan bahwa pembangunan PLBD di lokasi yang sudah disepakati tidak layak untuk dilaksanakan pada masa sekarang, dengan dalih bahwa dana yang dibutuhkan untuk pembangunannya sangat besar. Padahal masalah yang sebenarnya terletak pada persoalan restu dari pemerintah pusat, yang menilai proyek pembangunan infrastruktur di Serudong belum terlalu urgen untuk dilaksanakan sekarang.

Sedangkan pihak Indonesia dalam hal ini adalah Pemerintah Provinsi Kalimantan Timur telah berupaya untuk mematuhi semua hasil kesepakatan, dengan memenuhi semua kewajibannya yang telah diamanatkan dalam perjanjian. Ini mengindikasikan bahwa Indonesia adalah partisipan rezim perjanjian dengan derajat kepatuhan (compliance) yang tinggi. Namun bukan berarti Indonesia bertindak sempurna dalam mentaati perjanjian. Perilaku compliance Indonesia tersebut dapat dinilai sebagai sebuah kepatutan yang harus dilakukan, karena semua tawaran kerjasama yang terangkum dalam 7 (tujuh) kertas kerja tersebut merupakan usulan dari Indonesia. Sehingga bagi Indonesia alasan mentaati hasil kesepakatan selain sebagai upaya untuk mencapai kepentingan nasional, juga untuk alasan tanggung jawab moral selaku pihak yang mengusulkan, serta bentuk kesadaran Indonesia yang memahami bahwa rezim adalah norma yang harus dipatuhi (pacta sunt servanda).

\section{KEGAGALAN REZIM SOSEK MALINDO MENCIPTAKAN MEKANISME COMPLIANCE}

Adanya hasil kesepakatan yang tidak dilaksanakan oleh salah satu partisipan perjanjian (dalam hal ini adalah pihak Malaysia) tentu saja tidak lepas dari eksistensi rezim kerjasama Sosek Malindo yang tidak mampu menciptakan mekanisme compliance dalam strategi pengelolaannya.

Munculnya non-compliance dalam pelaksanakan hasil kesepakatan rezim Sosek Malindo Kaltim-Sabah, bukan hanya sekedar kurangnya tingkat kesadaran dari partisipan perjanjian. Akan tetapi juga lebih dikarenakan rezim Sosek Malindo tidak mengadung elemen-elemen mendasar yang dapat mempersuasi partisipan untuk mematuhi perjanjian, walaupun tanpa harus menggunakan instrumen sanksi.

Merujuk pada argumentasi management school yang menegaskan bahwa strategi yang paing efektif untuk menciptakan perilaku compliance adalah dengan menggunakan metode/pendekatan persuasi. Metode ini membutuhkan tiga elemen penting, yaitu: transparency, dispute settlement, capacity building.

Lantas bagaimana dengan keberadaan rezim Sosek Malindo Kaltim-Sabah dalam rangka menciptakan mekanisme compliance tersebut. Strategi apa yang dilakukan agar semua program kerjasama dapat terlaksana. Apakah rezim ini dipatuhi oleh para partisipannya.

Dalam pelaksanaaan hasil kesepakatan transparansi adalah kata kunci bagi terciptanya compliance. Elemen transparansi yang dimaksud dalam rezim adalah diseminasi informasi tentang performa para partisipan perjanjian. Transparansi dapat mempengaruhi pola 
interaksi strategis antar partisipan dalam mematuhi (compliance) perjanjian. Elemen ini mampu memfasilitasi ruang kerjasama bagi para aktor untuk membuat kebijakan yang independen dalam norma perjanjian. Transparansi juga memberikan jaminan kepastian kepada para aktor yang mematuhi perjanjian bahwa aktor lain juga akan melakukan hal yang sama. Dia juga dapat berfungsi sebagai instrumen penangkal (deterrence) bagi aktor yang bertindak non-compliance.

Jika diperhatikan dengan teliti dalam rezim kerjasama Sosek Malindo Kaltim-Sabah tidak ditemukan elemen transparansi tersebut. Hampir semua butir kesepakatan dibuat hanya berdasarkan pada muatan kepentingan masing-masing pihak. Sehingga ketika pada saat dieksekusi, pelaksanaan kesepakatan sering kali mengalami kendala seperti penundaan dan pembatalan, apalagi jika ternyata hasil kesepakatan tidak terlalu memberikan kontribusi yang signifikan bagi pencapaian kepentingan nasional masing-masing aktor.

Seperti yang terjadi pada hasil kesepakatan tentang proyek pembangunan PLBL dan PLBD yang tidak dipatuhi oleh Malaysia. Padahal di lain pihak, Indonesia secara optimal telah menjalankan hasil kesepakatan. Kondisi tersebut mengindikasikan bahwa dalam perjanjian Sosek Malindo Kaltim-Sabah tidak mengandung butir kesepakatan yang dapat menjamin kepastian berjalannya hasil kesepakatan.

Penjelasan selanjutnya menunjukkan bahwa kerjasama Sosek Malindo mempunyai struktur organisasi yang mapan. Dalam birokrasi organisasi terdapat agenda sidang yang dilaksanakan setiap tahun untuk membicara program-program kerjasama pembangunan di perbatasan, termasuk juga mendiskusikan perbedaan-perbedaan antara Indonesia dan Malaysia.

Namun titik persoalannya terletak pada struktur organisasi Sosek Malindo ini yang memiliki mekanisme pengambilan keputusan yang sangat rumit dan panjang. Membutuhkan waktu yang lama dan proses yang panjang untuk bisa menghasilkan sebuah kebijakan atas permasalahan tertentu.

Terhambat dan tertundanya realisasi dari program- program kerjasama yang disepakati dalam perjanjian Sosek Malindo disebabkan oleh mekanisme pengambilan keputusan yang panjang tersebut. Hal ini tentu saja memperlambat proses realisasi hasil kesepakatan Sosek Malindo di tingkat daerah seperti yang juga dialami oleh Kaltim dan Negeri Sabah. Akibat dari mekanisme pengambilan keputusan yang panjang tersebut berdampak pada manajemen compliance rezim, yang semestinya dapat terlaksana pada waktu yang telah direncanakan tapi harus tertunda karena harus menunggu restu dan persetujuan dari struktur sidang organisasi yang lebih tinggi.

Lebih lanjut dapat dijelaskan bahwa keterbatasan kapasitas partisipan dalam perjanjian internasional dapat menjadi kendala yang serius pada tataran implementasi kesepakatan. Limited capacity yang dimaksud adalah dalam hal kemampuan teknis, kapabilitas birokrasi, dukungan finansial, termasuk juga kewenangan. Kendala keterbatasan kapasitas ini dapat mempengaruhi mekanisme compliance pada sebuah rezim.

Berkaitan dengan rezim Sosek Malindo KaltimSabah, yang menjadi kendala utama adalah terbatasnya wewenang yang dimiliki oleh Pemerintah Provinsi Kalimantan Timur dan Pemerintah Negeri Sabah. Kedua belah pihak menyadari bahwa bidang-bidang kerjasama yang disepakati dalam forum KK/JKK Sosek Malindo Tingkat Provinsi Kaltim dan Negeri Sabah cenderung terlalu melebar dan melampaui kewenangan yang dimiliki oleh kedua belah pihak.

Untuk isu pembangunan PLBL dan PLBD masingmasing pihak memang harus menunggu persetujuan dari pemerintah pusat karena memang merupakan domain kewenangan pemerintah pusat. Tidak terlaksananya kesepakatan pembangunan PLBL dan PLBD yang ada di wilayah perbatasan Malaysia dikarenakan pemerintah pusat Kuala Lumpur tidak memberikan restu/persetujuan. Sangat tidak mungkin memang bagi pemerintah Negeri Sabah untuk melanjutkan proyek pembangunan PLBL dan PLBD tanpa dukungan dari pemerintah pusat. Kondisi inilah yang mempengaruhi mekanisme compliance dalam implementasi rezim kerjasama Sosek Malindo. 


\section{IMPLIKASI KEGAGALAN TERHADAP HASIL KESEPAKATAN}

\section{DAN PERILAKU AKTOR}

Kegagalan rezim perjanjian kerjasama Sosek Malindo dalam menciptakan mekanisme compliance tentu saja berimplikasi serius terhadap pelaksanaan hasil kesepakatan. Implementasi program-program kerjasama pembangunan di daerah perbatasan dalam kerangka Sosek Malindo Kaltim-Sabah sering mengalami beberapa hambatan serius. Program kerjasama yang sudah dirancang dan sudah disepakati secara bersama-sama oleh kedua belah pihak tidak dapat berjalan secara efektif karena adanya compliance problem.

Implikasi yang paling serius adalah tidak terpenuhinya beberapa hasil kesepakatan, seperti: tidak terrealisasinya rencana pembangunan PLBL di Sungai Imam, Malaysia dan pembangunan PLBD di Serudong, Malaysia. Dengan tidak terrealisasinya 2 (dua) hasil kesepakatan tersebut, maka dapat berpengaruh pada proses pelaksanaan program kerjasama yang lain.

Ketidakmampuan rezim kerjasama Sosek Malindo untuk menciptakan mekanisme compliance dalam strategi pengelolaannya tidak hanya mempengaruhi efektifitas pelaksanaan program hasil kesepakatan kerjasama, akan tetapi juga berimplikasi pada perilaku masing-masing pihak yang memformulasi kesepakatan kerjasama. Perilaku Indonesia jauh lebih patuh dibandingkan dengan Malaysia, Indonesia menjalankan semua hasil kesepakatan sementara Malaysia tidak menjalankan beberapa hasil kesepakatan.

\section{KESIMPULAN}

Isu pembangunan di daerah perbatasan memang telah menjadi perhatian yang sangat serius pada level nasional. Bagi pemerintah Republik Indonesia pembangunan di daerah perbatasan berkaitan erat dengan misi pembangunan nasional, terutama untuk menjamin keutuhan dan kedaulatan wilayah, pertahanan dan keamanan nasional serta peningkatan kesejahteraan masyarakat. Dalam rangka mewujudkan kepentingan tersebut, maka strategi yang dibutuhkan oleh pemerintah Republik Indonesia adalah dengan menjalin kerjasama internasional.

Salah satu kerjasama internasional yang dilakukan adalah Sosek Malindo. Kerjasama Sosek Malindo merupakan salah satu bentuk kerjasama internasional yang memiliki makna strategis bagi kedua negara dalam upaya untuk mempercepat proses pembangunan di daerah perbatasan masing-masing negara.

Dalam perkembangannya kerjasama Sosek Malindo tingkat daerah Kalimantan Timur dan peringkat Negeri Sabah menyepakati 7 (tujuh) kertas kerja yang meliputi: pembangunan PLBL, pembangunan PLBD, pencegahan dan penanggulangan kegiatan penyelundupan, hubungan sosial, bidang pendidikan, bidang kesehatan, bidang ekonomi dan perdagangan. Namun ada dua kertas kerja yang tidak terlaksana dengan sempurna, yaitu: kesepakatan tentang pembangunan PLBL di Sungai Imam dan PLBD di Serudong.

Tidak terlaksananya 2 (dua) kesepakatan tersebut merupakan bentuk tindakan non-compliance yang dilakukan oleh pihak Malaysia. Perilaku Malaysia ini ditengarai adanya motif kepentingan. Bagi Malaysia membangun infrastruktur perbatasan berupa fasilitas PLBL dan PLBD bukan merupakan bagian dari kepentingan prioritas. Sementara di lain pihak, Indonesia telah memenuhi semua hasil kesepakatan kerjasama termasuk membangun fasilitas PLBL di Sungai Lamijung dan PLBD di Simanggaris. Perilaku compliance ini telah dibuktikan dengan merampungkan proyek pembangunan pelabuhan Sungai Lamijung yang ditetapkan sebagai PLBL di wilayah perbatasan Indonesia. Selain itu, Indonesia juga terus meningkatkan kualitas pembangunan infrastruktur pendukung (seperti: jalan, jembatan, drainase) yang menuju ke arah PLBD di Simanggaris.

\section{ENDNOTES}

1 Keterangan ini disampaikan oleh Samsul, SH (Kasubbag Kerjasama Perbatasan Pemerintah Kabupaten Nunukan), hasil wawancara pada tanggal 10 November 2010

2 Untuk KK. Sosek Malindo Tingkat Daerah Provinsi Kalimantan Timur diketuai oleh Prof.DR.Adri Patton, M.Si (Kepala Badan Pengelolaan Kawasan Perbatasan, Pedalaman dan Daerah Tertinggal) yang baru saja menjabat menggantikan Drs. Abdussamad (Mantan Asisten I Sekprov. Kaltim) yang memasuki masa jabatan pensiun. Sedangkan 
untuk JKK Sosek Malindo Peringkat Negeri Sabah diketuai oleh Yang Berbahagia. Datuk Maznah BTE Abdul Ghani (Timbalan Setiausaha Kerajaan (1) Negeri Sabah.

\section{BIBLIOGRAFI}

Asaddin, Fuad. 2010. Hasil Pelaksanaan Rapat Teknis. (Online), (http:www. tastawima.com, diakses 26 Juli 2010).

Asaddin, Fuad. 2010. Sinergitas Pengembangan Potensi. (Online), (http:www. tastawima.com, diakses 26 Juli 2010)

Asaddin, Fuad. 2010. TOR Kerjasama Sosek Malindo perlu disempurnakan. (Online), (http:www. tastawima.com, diakses 25 November 2010)

Banyu Perwita, Anak Agung \& Yayan Gani. 2005. Pengantar Ilmu Hubungan Internasional. Bandung: Rosda.

Bappeda Kab. Nunukan. 2008. Profil Kabupaten Nunukan 2008. Pemerintah Kabupaten Nunukan

Bappeda Provinsi Kaltim. 2009. Laporan Perkembangan Kerjasama Sosial Ekonomi Malaysia-Indonesia (Tingkat Daerah Kalimantan Timur-Peringkat Negeri Sabah. Pemerintah Provinsi Kalimantan Timur.

BPS Kab. Nunukan. 2009. Kabupaten Nunukan Dalam Angka 2009. Pemerintah Kabupaten Nunukan.

Carlsnaes, Walter .Thomas Risse \& Beth A. Simmons. 2002. Handbook of International Relations. London: SAGE Publication.

Chayes, Abram \& Antonia Handler Chayes. 1993. On Compliance. Dalam International Organization. Vol. 47 No.2 (Spring). University of Wisconsin Press, The MIT Press. (Online). (http:www.jstor.org)

Chayes, Abram \& Antonia Handler Chayes. 1995. The New Sovereignty: Compliance with International Regulatory Agreement. London: Harvard University Press.

Cheboud, Elias \& Hanafi Rais. 2010. Materi Perkuliahan Research Method. Tidak dipublikasikan.

Direktorat Jenderal Kerjasama Asean. 2007. Asean Selayang Pandang. Departemen Luar Negeri Rl, Jakarta.

Farouk Ishak, Awang. 2003. Membangun Wilayah Perbatasan Kalimantan Dalam Rangka Memelihara dan Mempertahankan Integritas Nasional. Jakarta: Sinar Grfika.

Haas, B. Ernst.1982. Word can hurt you; or, who said what to whom about regimes. Dalam International Regimes. London: Cornell University Press.

Husein, Machnun. 1986. Etika Pembangunan dalam Pemikiran Islam di Indonesia. Jakarta: CV. Rajawali.

Irewati, Awani. 2005. Sikap Indonesia dalam Menghadapi Kejahatan Lintas Negara: Ilegal Logging di Kalimantan Barat dan Kalimantan Timur. Dalam Jurnal Politik, Vol.2 No. 1. Jakarta: LIPI.

Jonsson, Christer \& Jonas Tallberg. 1998. Compliance and Post Agreement Bargaining. Dalam European Journal of International Relations. London: SAGE Publications.

Kementerian Perencanaan Pembangunan Nasional/BAPPENAS. 2010. RPJNM 2010-2014, Direktorat Kawasan Khusus dan Daerah Tertinggal, Jakarta.

Koespramoedyo, Deddy dkk. 2003. Strategi dan Model Pengembangan Wilayah Perbatasan Kalimantan. Direktorat Pengembangan Kawasan Khusus \& Tertinggal Deputi Bidang Otonomi Daerah \& Pengembangan Regional BAPPENAS, Jakarta.
Krasner, D. Stephen. 1984. International Regimes. London: Cornell University Press.

Mingst, Karen. 1999. Essentials of International Relations. New York \& London: Norton \& Company.

Murray, Neil \& Geraldine Hughes. 2008. Writing Up Your University Assignment and Research Projects: A Practical Handbook. New York: MacGraw Hill, Open University Press.

Olson, C. Olson \& A.J.R. Groom. 1991. International Relations Then and Now: Origins and trends in interpretation. London: HarperCollins Academic.

Puchala, J. Donald \& Raymond F. Hopkins. 1992. International regimes: lessons from inductive analysis. Dalam International Regimes. London: Cornell University Press.

Risalah Sidang ke-15 JKK/KK Sosek Malindo Peringkat Negeri SabahTingkat Daerah Kalimantan Timur.

Siburian, Robert. 2004. Kondisi Perkonomian Masyarakat Perbatasan: Entikong dan Nunukan. Dalam Masyarakat Indonesia: Majalah IImu-ilmu Sosial Indonesia, Jilid XXX, No. 2. Jakarta: LIPI.

Singarimbun, Irawati. 1989. Metode Penelitian Sosial. Jakarta: LP3ES.

Wolfer, Loreen. 2007. Real Research: Conducting and Evaluating Research in the Social Sciences. Boston: Pearson Education Inc.

Young, R. Oran. 1982. Regime dynamics: the rise and fall of international regimes. Dalam International Regimes. London: Cornell University Press.

\section{Wawancara}

Adri Patton, Prof.DR. (Kepala BPKPPDT Provinsi Kalimantan Timur) Fuad Asaddin, M.Si (Kabiro Perbatasan Penataan Wilayah Prov. Kaltim) Hanafiah, SE (Kepala BAPPEDA Kabupaten Nunukan)

Loiseana Benito, dr (Dokter Umum Puskesmas Sungai Nyamuk, Sebatik Induk)

Putu Eko Prasetyo (Kasi Penindakan, Penyidikan Bea \& Cukai, Kab. Nunukan)

Rahmad, drg (Kepala Puskesmas Sungai Nyamuk, Sebatik Induk) Rinsan Siagian (Kasi Perbendaharaan Bea \& Cukai, Kab. Nunukan) Samsul, SH (Kasubbag Kerjasama Perbatasan Kabupaten Nunukan) 